\title{
LA TITULARIDAD DEL CUIDADO PERSONAL Y EL EJERCICIO DE LA RELACIÓN DIRECTA Y REGULAR A LA LUZ DE LA JURISPRUDENCIA ACTUAL
}

[Guardianship of Personal Care and the Exercise of Direct and Regular Relationship in the Light of the Current Jurisprudence]

\author{
María Soledad Quintana VillaR* \\ Pontificia Universidad Católica de Valparaíso, Chile
}

\begin{abstract}
RESUMEN
El trabajo muestra la aplicación jurisprudencial de dos de los efectos más importantes de la autoridad parental, cuales son: el cuidado personal y la relación directa y regular conforme con la ley actualmente vigente. Manifiesta cómo los principios rectores de la ley, o sea, el del interés superior del hijo y de la corresponsabilidad, son tomados en consideración por los jueces, así también como los criterios dados por el legislador para fallar en estas materias.
\end{abstract}

Palabras Clave

Interés superior del menor - Cuidado personal - Relación directa y regular Corresponsabilidad.

\section{ABStract}

This work presents the jurisprudential application of two of the most important effects of parental authority, which are: personal care and direct and regular relationship, according to the current law. It states the manner in which the ruling principles of the law, that is, the best interest of the child and joint responsibility, are taken into account by the judges, as well as the criteria given by the legislator to pronounce judgement on these matters.

\section{KEYWORDS}

Best interest of the child - Personal care - Direct and regular relationship Joint-responsibility.

RECIBIDO el 30 de octubre y ACEPTADO el 22 de diciembre de 2014

* Licenciada en ciencias jurídicas y licenciada en filosofía y educación por la Pontificia Universidad Católica de Valparaíso. Profesora adjunta de la Facultad de Ciencias Económicas y Administrativas de la Pontificia Universidad Católica de Valparaíso. Dirección postal: Av. Brasil 2830, piso 5, Valparaíso, Chile. Dirección electrónica: maria. quintana@ucv.cl 


\section{TITUlARIDAD DEL CUIDADO PERSONAL}

En un artículo anterior ${ }^{1}$ me referí al tema del cuidado personal de los hijos y a cómo este ha cobrado cada vez mayor relevancia debido a múltiples factores, entre ellos, el aumento de las separaciones conyugales, el desinterés de las actuales parejas por contraer matrimonio y la equiparación de los derechos de los hijos matrimoniales y no matrimoniales ${ }^{2}$.

La titularidad del cuidado personal ha sufrido un cambio sustancial con la entrada en vigencia de la Ley $\mathrm{N}^{\circ} 20.680$, mientras en la antigua legislación la atribución era legal, pues el derogado artículo $225 \mathrm{CC}$. en su inciso primero declaraba: "Si lospadres viven separados, a la madre toca el cuidado personal de los hijos"; en la ley actual, la atribución es, en primer lugar, convencional, $\mathrm{y}$, en subsidio de acuerdo entre los progenitores, se establece que los hijos permanezcan con quien están conviviendo (artículo 225 inciso $3^{\circ} \mathrm{CC}$ ).

Son apreciables en las disposiciones de la Ley $\mathrm{N}^{\circ} 20.680$ y en la aplicación jurisprudencial de ella, dos principios rectores: el primero, del interés superior de los hijos; el segundo, de la corresponsabilidad de ambos padres en el cuidado personal, la crianza y educación de los hijos. El interés superior es un concepto no acotado, sino, por el contrario, abierto, pues permite subsumir en él todo aquello que, en cada caso concreto, aparezca como lo más beneficioso para el desarrollo integral del menor y para la satisfacción de sus necesidades, físicas, psíquicas y espirituales. Al decir de la Corte Suprema es un "[...] principio fundamental e inspirador de nuestro ordenamiento jurídico, de relevancia transversal en la legislación de familia y de menores. Así lo dispone por lo demás, entre otros, el artículo 222 del Código Civil y, aún cuando su definición se encuentra en desarrollo o constituya un concepto indeterminado, cuya magnitud se aprecia cuando es aplicado al caso concreto, puede afirmarse que el mismo, alude al pleno respeto de los derechos esenciales del niño, niña o adolescente, buscándose a través del mismo, el asegurar el ejercicio y protección de los derechosfundamentales de los menores y posibilitar la mayor satisfacción de todos los aspectos de su vida, orientados al desarrollo de su personalidad"3.

El segundo de los principios mencionados, el de la corresponsabilidad, es explicitado por el nuevo legislador tomando en consideración que los hijos necesitan para su equilibrio emocional y el mejor desarrollo de sus

\footnotetext{
${ }^{1}$ Quintana Villar, María Soledad, Legislación y jurisprudencia sobre el cuidado personal y relación directa y regular con él, en Revista de Derecho de la Pontificia Universidad Católica de Valparaiso, 33 (2009), pp. 149-172.

${ }^{2} \mathrm{El}$ porcentaje de niños nacidos fuera del matrimonio al mes de julio del presente año de 2014 ha superado el 70\%, según datos proporcionados por el Registro Civil e Identificación.
}

${ }^{3}$ Corte Suprema, causa rol 3666-2014, considerando $6^{\circ}$. 
potencialidades de ambos progenitores, siempre que ello no los perjudique. Como comentara en una obra anterior, ${ }^{4}$ existe una jerarquía entre ambos principios, pues el más importante es, sin duda, el interés superior del menor. El de la corresponsabilidad debe subordinarse a aquel.

1. Ponderación de los criterios establecidos por la ley para la atribución del cuidado personal.

Se advierte que la nueva ley obliga a los jueces a un análisis más acabado de todas las circunstancias que confluyen en el caso en estudio, en comparación con la ley derogada en la que el cuidado personal le correspondía a la madre, salvo acuerdo en contrario de los progenitores o que se demostrara que esta sufría de una causal de inhabilidad. Al respecto, los jueces, por regla general, exigían que se acreditase la incapacidad de la madre de manera irrefragable.

En cambio, ahora, el juez, cuando se discute ante él, respecto del establecimiento del régimen y acerca del ejercicio del cuidado personal, debe tener presente y ponderar los criterios enunciados en el artículo 225-2 CC., esto es, "a) La vinculación afectiva entre el hijo y sus padres, y demás personas de su entorno familiar; b) La aptitud de los padres para garantizar el bienestar del bijo y la posibilidad de procurarle un entorno adecuado, según su edad; c) La contribución a la mantención del hijo mientras estuvo bajo el cuidado personal del otro padre, pudiendo hacerlo; d) La actitud de cada uno de lospadrespara cooperar con el otro, a fin de asegurar la máxima estabilidad al hijo y garantizar la relación directa y regular, para lo cual considerará especialmente lo dispuesto en el inciso quinto del articulo 229; e) La dedicación efectiva que cada uno de lospadres procuraba al hijo antes de la separación y, especialmente, la que pueda seguir desarrollando de acuerdo con sus posibilidades; f) La opinión expresada por el hijo; g) El resultado de los informes periciales que se haya ordenado practicar; h) Los acuerdos de los padres antes y durante el respectivo juicio; i) El domicilio de los padres, $y \mathrm{j}$ ) Cualquier otro antecedente que sea relevante atendido el interés superior del hijo".

Es digna de resaltar la exhaustividad mostrada por el legislador en esta enumeración, iluminando, de esta manera, al sentenciador en el examen y resolución del litigio que está conociendo. Además, el último de los criterios mencionados es un claro reconocimiento de que puede haber otro antecedente que, en el caso concreto, sea relevante y no esté incorporado en la disposición.

Resulta pertinente citar la sentencia de la Corte de Apelaciones de Puerto Montt, causa rol 197-2013, que subsana lo resuelto por el juez de familia,

${ }^{4}$ Quintana Villar, María Soledad, Derecho de familia (Valparaíso, Ediciones Universitarias de Valparaíso, 2013), p. 323. 
quien no había considerado, en el caso sub iudice, varios de los criterios formulados en la disposición en comento, como la vinculación afectiva entre el hijo y sus padres y demás personas de su entorno familiar, la aptitud de los padres para garantizar el bienestar del hijo y la opinión de los menores, entre otros.

La Corte expresa en el considerando $4^{\circ}$ de la sentencia: "Que, en cuanto a la acción de cuidado personal, a la luz de lo establecido en los articulos 225 y 225- 2 del Código Civil, existen criterios que se deben tomar en consideración al momento de conocer y juzgar sobre el cuidado personal de los hijos de aquellos padres que viven separados, criterios y circunstancias de carácter general que deben ponderarse en su conjunto y que apuntan necesariamente al interés superior del niño, principio respecto del cual deben ceder todas las demás apreciaciones. I Asi las cosas, el hecho de que la madre de los menores de autos haya mantenido una actitud negativa de cara al ejercicio del derecho a relación directa y regular por parte del padre, a juicio de estos sentenciadores no resulta bastante para modificar la custodia personal de éstos. I En efecto, tal circunstancia, siendo indeseable, debe ponderarse, como se ha venido diciendo, junto a los demás criterios proporcionados por la norma, ejercicio que una vez efectuado recomienda mantener el cuidado personal a cargo de la madre. La existencia de una vinculación afectiva de los menores con la madre y demás personas que conforman el grupo familiar materno que aparece cohesionado, un entorno que garantice su bienestar y la mantención del hábitat al que están acostumbrados casa, ciudad, colegio, amistades, etc., adquiere prioridad al momento de decidir con quién deben vivir, crecer y desarrollarse, más allá de los derechos de las partes y de su legítimo ejercicio".

Los magistrados deben, pues, atender a todos y a cada uno de los criterios establecidos por el legislador y no realizar una aplicación aislada de ellos, dado que, de este modo, sería más factible transgredir el interés superior del menor al no atender a aspectos que son importantes para el normal desenvolvimiento de sus facultades.

Es cierto que puede darse la situación, y ha ocurrido en la práctica, que se produzcan discordancias entre unos y otros, debiendo, el juez, entonces, elegir cuál es el que mejor armoniza con el interés superior del menor que debe siempre privilegiarse aún por sobre los deseos y los legítimos derechos de los adultos involucrados.

\section{Mantención de la titularidad del cuidado personal en quien lo detenta.}

Examinando las sentencias, se aprecia cómo los jueces estiman, la mayoría de las veces, que el interés superior del menor se logrará más cabalmente manteniendo la titularidad del cuidado personal en quien actualmente la detenta, puesto que el cambio de cuidador entrañaría un desarraigo del 
entorno habitual del menor, con las consecuencias que ello podría acarrear en su estabilidad psíquica, redundando, por ende, en su desarrollo integral, pues, al separarlo de aquello que constituye su ambiente, se lo sometería, una vez más - muy probablemente-, a otro proceso de adaptación.

Así, leemos, en el considerando cuarto de la causa rol 79-2014 de la Corte de Apelaciones de Concepción: "Que, se comparte el parecer jurídico del tribunal a quo, en el sentido que la mantención de las condiciones vigentes de cuidado constituye la opción menos perjudicial a los intereses superiores de los niños en cuestión, preservando asi el arraigo actual de ellos con el hogar de la actora y sus familiares cercanos, con su comunidad educacional y de afectos $y$, además, porque ese fue su deseo, manifestado en la audiencia reservada".

¿Cuáles eran las condiciones vigentes de cuidado en el caso sub iudice? Que la abuela materna continuara ejerciendo la custodia de sus nietos, cuidado personal que ella detentaba ya de facto. El fallo aplica dos de los principios directrices en estas materias, no solo el del interés superior -que se manifiesta debe primar por sobre el de los adultos implicados-, también el derecho de los menores a ser oídos 5 . Además, dicha resolución cumple con el mandato legislativo, en orden a establecer el régimen de relación directa y regular con sus progenitores. Se lee en el considerando quinto: "Que lo anterior no implica de manera alguna la separación definitiva de los niños con sus padres, pues en ejercicio del régimen de relación directa y regular fijado en la sentencia, podrán recomponer ofortalecer el vinculo afectivo y la posibilidad de que, en un futuro cercano, vivan en un mismo hogar".

De la sentencia en análisis queda claro, también, que, en ocasiones, no se puede optar por lo mejor, sino por lo que es menos dañino, por lo que, se considera, perjudicará en menor medida al hijo, pues lamentablemente, en estas materias, muchas veces no cabe aplicar lo óptimo para este sino lo que se piensa le será menos nocivo. Asimismo, se patentiza, que en el otorgamiento de la titularidad del cuidado personal, juegan un rol importante las personas que están vinculadas con la que gozará de ella, en otras palabras, la familia extensa del titular, aplicando el criterio formulado en la letra a) del artículo 225-2 CC.

Se puede advertir un razonamiento similar en fallos de la Corte Suprema que estiman como una transgresión de los derechos del niño el sustraerlo del

${ }^{5}$ Por su parte, la Corte de Apelaciones de San Miguel, en la causa rol 275-2014, entiende por el derecho de los menores a ser oídos, el "derecho a expresar sus opiniones en los diferentes ámbitos de su vida y desarrollo, entre ellos el ámbito familiar, social, escolar y judicial. Si bien, la obligación de escuchar al niño no implica aceptar sus deseos, su manifestación constituye un importante factor que debe analizarse en el contexto de todos los demás antecedentes incorporados al proceso a fin de que contribuy a a que la decisión que se adopte en definitiva sea la más favorable y adecuada a su respecto". 
ambiente que le proporciona un sentimiento de estabilidad, desarraigo que provocaría una alteración de su equilibrio emocional y afectaría su desarrollo. A vía ejemplar, en el considerando tercero de la causa rol 11782-2014, los ministros expresan: "Que de la lectura de la sentencia de primera instancia, confirmada por la impugnada, se advierte quepara negar lugar a la demanda de cuidado personal se dio por establecido que la demandante no logró acreditar que alpadre de la menor le asista alguna inhabilidad que haga procedente privarlo del cuidado personal que ejerce desde hace más de dos años por acuerdo de las partes; concluyéndose que tal decisión guarda perfecta conexión con el principio rector del marco regulatorio de los derechos sustantivos establecidos en favor de los menores de edad, esto es, el interés superior del niño, ya que una decisión diferente a la adoptada constituiría una evidente vulneración de los derechos de la niña a vivir en un ambiente que le asegura el sentimiento de pertenencia, esencial para su normal desarrollo"6.

Igualmente, teniendo presente la corta edad de la menor y la teoría del apego, la Corte de Apelaciones de Santiago, confirma la sentencia del tribunal de primera instancia, que había acogido la opinión de la Consejera Técnica. De esta forma, a pesar de reconocer que el padre, demandante reconvencional del cuidado personal de su hija, poseía las habilidades parentales necesarias para ejercerlo y que existía un fuerte vínculo afectivo de la niña tanto con él como con las demás personas de su entorno familiar, se decide mantener la titularidad en la madre, pues actuar de otra manera, se argumenta, podría perjudicar el adecuado desenvolvimiento de la niña. ${ }^{7}$

Nuevamente la Corte Suprema, en causa rol 561-2014, aplica el mismo criterio, concediendo el exequátur necesario para que pueda cumplirse, en Chile, la sentencia dictada por el Cuarto Juzgado de Familia de la Primera Circunscripción Judicial de Mendoza, Argentina, que había acogido la demanda de guarda de menor -un adolescente-, otorgándosela a la abuela paterna con quien este siempre había vivido. Los ministros adujeron que, aunque no existe tratado entre Chile y Argentina de cara al cumplimiento de resoluciones pronunciadas en los respectivos países, como tampoco hay constancia sobre una posible situación de reciprocidad, la sentencia respecto de la cual se pide el exequátur no contraviene las leyes patrias ni se opone a la jurisdicción nacional, puesto que la madre, quien según nuestro ordenamiento jurídico detentaría el cuidado personal, dado el fallecimiento del padre, lo había cedido a la abuela paterna y el adolescente se encuentra convenientemente integrado en su grupo familiar, según consta en autos.

\footnotetext{
${ }^{6}$ En el mismo sentido, Corte Suprema, causas rol 10358-2013 y 21576-2014.

${ }^{7}$ Corte de Apelaciones de Santiago, causa rol 1409-2014.
} 


\section{Modificación de la titularidad del cuidado personal en atención al equi-} librio emocional del menor.

En cambio, hay sentencias en las que se altera la titularidad del cuidado personal cuando la estabilidad y el equilibrio emocional del menor se pueden lograr de mejor manera otorgándose el ejercicio al otro de los padres. De este modo, falló la Corte de Apelaciones de Valparaíso en el considerando quinto de la causa rol 110-2014: "Que estando establecido en estos autos que el menor de no permanecer con su padre desde que sale del colegio hasta que su madre vuelve del trabajo, tendría que estar solo atendido que no se divisa que los progenitores hayan determinado algo diferente, no cabe duda que a pesar de no existir ninguna inhabilidad de parte de la madre para ejercer el cuidado de su hijo, como lo ha hecho siempre, un niño de tan corta edad requiere contar con una estabilidad ojalá permanente para desarrollarse y poder rendir en sus estudios en forma debida, razón por la cual se estima que si bien ambospadres tienen la aptitud para garantizar el cariño y el bienestar de su hijo, en estos momentos es su padre quien está en condiciones de procurarle un entorno más adecuado, razón por la cual estos sentenciadores comparten lo resuelto por el tribunal a quo, en cuanto establece que en la actualidad es el padre quien puede brindarle un mayor equilibrio emocional a su hijo".

No obstante, teniendo en cuentas la importancia que reviste para el hijo la relación con ambos progenitores, los magistrados confirman la resolución de la jueza de primera instancia en orden a ampliar el régimen de relación con la madre.

Siguiendo esta línea interpretativa, que deben primar las necesidades de los hijos por sobre los deseos e, incluso, los derechos de los padres, la Corte de Apelaciones de San Miguel, en la causa rol 275-2014 ya citada, confirma el otorgamiento del cuidado personal de los hijos al padre, cuidado personal que antes detentaba la madre, sosteniendo en el considerando sexto: "Que asi las cosas, por sobre los derechos y deseos de los padres, no inhabilitados para el cuidado de sus hijos, están las necesidades de los niños, que de acuerdo a las probanzas rendidas, requieren de estabilidad en todo ámbito, familiar, emocional, afectiva, social y educacional para el goce efectivo de sus derechos, entre ellos, el desarrollo físico y psíquico óptimo como personas, que atendido el devenir de sus vidas aparece afianzado en el entorno en que se han desenvuelto el último tiempo en que el padre ha desempeñado su rol prestándoles la atención necesaria en cuanto a escolarización, salud, contención y afecto, por lo que, como ya se ha expresado, un cambio de régimen no resulta aconsejable. [...]. Que conforme a lo razonado, el interés superior de los niños debe prevalecer por sobre el de los padres, puesto que dicho principio se traduce en brindarles a éstos un entorno de protección y apego filial, en aras de mantener su estabilidad emocional, el arraigo afectivo alcanzado y el óptimo desarrollo de su personalidad, lo que en 
Las condiciones acreditadas, tal como lo sostuvo la sentencia recurrida solo puede verificarse viviendo ambos niños juntos, bajo un mismo techo al cuidado de su padre vislumbrándose como positivo el régimen comunicacional con la madre establecido por la juez de la instancia".

Estas sentencias son una expresión fehaciente de que la Ley $\mathrm{N}^{\circ} 20.680$ significa un progreso loable, en comparación con la anterior, en pro del logro del interés superior del menor, al permitirle desarrollarse en el ambiente más propicio para su realización personal y para el mejor desenvolvimiento de sus potencialidades.

Recordemos que, bajo el imperio de la ley derogada, los jueces, por regla general, no modificaban la titularidad del cuidado personal cuando la detentaba la madre invocando el antiguo artículo 225 CC. y aduciendo que, por orden natural, a ella le correspondía ejercerlo ${ }^{8}$.

\section{De la atribución del cuidado personal a un tercero.}

En el examen de las resoluciones judiciales se evidencia, también, que no existe consenso en la jurisprudencia respecto de a quién le corresponde el ejercicio del cuidado personal cuando es un tercero la persona que lo ha detentado por un cierto lapso, los progenitores no han incurrido en causal de inhabilidad y si bien se han separado del menor, no lo han abandonado.

$\mathrm{Al}$ respecto, citaré una sentencia de 18 de junio de 2013, es decir, dictada tres días antes de que entrara en vigor la Ley $\mathrm{N}^{\circ} 20.680$, pero habiendo sido esta ya promulgada, sentencia que le concede el cuidado personal del menor a su abuela materna, en circunstancias que sus padres no incurrían en causal de inhabilidad. Se afirma en los considerandos: $4^{\circ}:$ "Que, de acuerdo a lo previsto en los artículos 225, inciso tercero, 226 y 228 del Código Civil, las causales que pueden afectar a los progenitores e impedir el ejercicio del cuidado personal respecto de sus hijos, son las siguientes: a) cuando el padre o la madre en quien se ha radicado la tuición de los hijos, los maltraten; b) cuando elpadre o la madre en su caso, descuide a los hijos; c) cuando respecto de cualquiera de ellos concurra 'otra causa calificada'; d) cuando el padre o la madre hubiere abandonado al hijo; e) cuando a cualquiera de ellos afecte una inhabilidad fisica o moral. El legislador señaló causales especificas en virtud de las cuales es dable modificar la norma legal, contenida en el mencionado artículo 225, pero también consagró una causal genérica, la de 'otra causa calificada', es decir, dejó entregado al juez del fondo, en cada caso concreto, determinar si es conveniente para el niño privar a los padres de su cuidado para entregarlo a

${ }^{8}$ En este sentido, Corte Suprema, causas rol 1178-2006, 3097-2008 y 1789-2009; Corte de Apelaciones de Puerto Montt, causa rol 870-2008; Corte de Apelaciones de Santiago, causa rol 565-2009. 
un tercero"; 6: "Que si bien el cuidado personal de los hijos corresponde a sus padres, la interpretación armónica de las normas citadas permite concluir que el juez de la causa puede modificar la regla del artículo 225 del Código Civil y privar a los progenitores de dicho cuidado y entregarlo a un tercero (debiendo preferirse para estos efectos a los consanguineos más próximos y sobre todo a los ascendientes), al configurarse algunas de las situaciones descritas en los motivos anteriores que los inhabilitan para ello o porque el interés superior del menor asi lo aconseje".

No puedo dejar de señalar que los ministros no fueron fieles al tenor de las disposiciones citadas, puesto que fusionaron las dos primeras -los artículos 225 y 226 CC.-, en circunstancias que el artículo 225 CC. discurría respecto de la posible inhabilidad de uno de los progenitores, en cuyo evento, el juez estaba facultado para entregar la custodia al otro de los padres, no mencionándose un tercero. Mientras que la segunda -el artículo 226 CC.expresaba que se podría confiar esta a un tercero "en caso de inhabilidad fisica o moral de ambos padres2.

Coincido con el voto disidente de los ministros Pierry y Brito, quienes fueron de la opinión de acoger el recurso de nulidad sustancial y, en consecuencia, dictar sentencia de reemplazo que rechazara la demanda, por cuanto el fallo impugnado habría vulnerado los artículos 225 y 226 CC., ya que la interpretación armónica y sistemática de dichas disposiciones en relación con el artículo 42 de la Ley $\mathrm{N}^{\circ} 16.618$, según sostuvieron los ministros disidentes: "permite concluir que para que el juez pueda privar del cuidado personal a los padres y entregarlo a un tercero es necesaria la concurrencia de alguna causal de inhabilidad legal respecto de aquéllos, de manera que la sentencia impugnada incurre en los yerros denunciados en el arbitrio de casación en el fondo impetrado por los demandados".?

Otra sentencia, ya vigente la Ley $\mathrm{N}^{\circ} 20.680$, falla argumentando que corresponde a los padres el cuidado personal de los hijos, salvo que se encuentren inhabilitados o que los hubiesen abandonado o que, de detentarlo ellos, se afecte o ponga en riesgo el interés superior de los menores. En el caso sub iudice, la madre había dejado a su hijo al cuidado de una señora, yéndose a trabajar al sur del país, enviando mensualmente una suma de dinero para su mantención. Al cabo de dos años, decidió llevárselo. La cuidadora se negó a entregarlo aduciendo que se habían creado lazos de afecto entre el niño y ella. El tribunal de primera instancia rechazó la demanda de la madre de entrega inmediata del niño, sin embargo, los ministros de la Corte de Apelaciones decidieron revocar la sentencia y ordenar la entrega del menor a la madre, pero bajo seguimiento de la Oficina de Protección de Derechos de la Infancia

${ }^{9}$ Corte Suprema, causa rol 9536-2012. 
de Temuco para resguardar los derechos del niño y con el objeto que este mantuviese el contacto con la señora que lo había cuidado en ausencia de su madre y que representaba una figura significativa para él ${ }^{10}$.

En el pasado, ${ }^{11}$ me he referido latamente a situaciones similares en que existe conflicto entre uno de los progenitores y un tercero que ha tenido bajo su cuidado al menor. Empero, estimo que este asunto era de más fácil resolución, dado que no se configuraba abandono por parte de la madre que demandaba la entrega. En todo caso, los ministros se preocuparon de explicitar la necesidad de seguimiento de la Oficina de Protección de Derechos de la Infancia respectiva, asegurando, de esta manera, la relación con la cuidadora con la que se habían originado vínculos afectivos.

Un fallo de la Corte de Apelaciones de Coihaique de abril del presente año, revoca la sentencia del tribunal de primera instancia que acogía la demanda de la madre referente a restituirle el cuidado personal de su hijo. Es de destacar la prudencia demostrada por los ministros que, teniendo presente las capacidades parentales disminuidas de los progenitores, el bienestar del menor y habiéndosele oído, deciden, en pro de su interés superior, que se mantengan las condiciones actuales, esto es, el niño viviendo en el hogar paterno, bajo el cuidado de la abuela paterna. Declaran en el considerando $7^{\circ}$ : "En el caso sub judice, atendido al mérito de los antecedentes reunidos y las circunstancias que rodean a la situación actual del menor D. S., a juicio de estos sentenciadores, sacarlo del entorno familiar donde se ha sentido resguardado desde muy temprana edad, en donde no se ha reportado riesgo, bajo el cuidado y protección de su abuela paterna, sin escuchar sus deseos y sin cumplir pasos intermedios recomendables para no vulnerar su bienestar actual niperjudicar su desarrollo social, afectivo y psíquico, en aras del interés superior del niño, resulta aconsejable, por ahora, mantener al menor referido bajo el cuidado personal del demandado".

Además, los ministros decretan el ingreso de los progenitores y del niño a un programa de intervención, a fin de que, "previo diagnóstico de la dinámica familiar, disponga intervención y realice las coordinaciones pertinentes con otras instituciones de salud que correspondan, a fin de mejorar y fortalecer las habilidades parentales que se encuentran disminuidas, y entregar herramientas tendientes a superar la conflictiva familiar, y en el evento de ser necesario, se realicen las gestiones oportunas para que éstos retomen los tratamientos psiquiátricos y psicológicos que resulten pertinentes" ${ }^{12}$.

También en atención a las insuficientes habilidades parentales de los

\footnotetext{
${ }^{10}$ Corte de Apelaciones de Santiago, causa rol 493-2014.

${ }^{11}$ Quintana Villar, María Soledad, cit. (n. 1).

${ }^{12}$ Corte de Apelaciones de Coyhaique, causa rol 7-2014.
} 
progenitores, la Corte de Apelaciones de San Miguel, en causa rol 887-2013, confirma la sentencia de primera instancia que había resuelto decretar el cuidado personal del menor J.T.T.S. a favor de su tía abuela paterna.

La madre había apelado, demandando la revocación de la sentencia y solicitando se le confiriera el cuidado personal de su hijo.

El fallo es interesante desde varias perspectivas. Una de ellas es la demostración de que en estas materias, en lo referente a la prueba, rigen las reglas de la sana crítica. Recordemos que el legislador de la Ley $\mathrm{N}^{\circ} 20.680$ cuando enuncia los criterios que debe tomar en consideración el juez al fallar, hace referencia al informe de peritos, en el artículo 225-2 letra g). Pues bien, en la causa sub iudice, los informes periciales de las psicólogas son contradictorios. Los magistrados, tanto de primera instancia como de segunda, optaron por aquel que, aunque más lejano en el tiempo, concordaba de mejor manera con las otras pruebas rendidas en el juicio. Según este informe, "la peritada cuenta con pobres habilidades parentales respecto de la crianza de su hijo...que requieren ser reforzadas con el objeto de procurar una revinculación con su hijo $J$. T. en el contexto de un tratamiento psicológico, como el decretado, que tenga como fin lograr los objetivos señalados".

Otra-de las perspectivas interesantes- es que los jueces deciden privilegiar a un tercero de cara a la titularidad del cuidado personal, dadas las habilidades parentales disminuidas de la madre. Pero no a cualquier tercero, sino a la tía abuela con la cual había vivido el menor. $\mathrm{Al}$ respecto, expresan los ministros en el considerando séptimo: "la vital importancia del arraigo del menor en el seno de la familia de la demandante, cuyo tropiezo, como señala el fallo provocaria un daño emocional grave en su desarrollo integral".

Por fin, la preocupación demostrada en que se mantenga una relación sana y cercana entre el hijo y sus padres. Así, se lee en el mismo considerando: "Atento el sentenciador a lo anterior [...] ha dispuesto a objeto de velar por su adecuada revinculación con el hijo que doña $K$. S. reciba la debida asistencia psicológica por el tiempo que se estime necesario para los fines perseguidos". Y, respecto de la relación con el padre, se acoge su reclamo y se fija un régimen que le permita cumplirlo.

\section{Acuerdo de vida en pareja y titularidad del cuidado personal.}

El 7 de octubre del presente año, el Senado envió a la Cámara de Diputados, en segundo trámite constitucional, el proyecto de ley que crea el Acuerdo de Vida en Pareja. En su artículo 45 ordena agregar un tercer inciso al artículo 226 CC.: "No obstante lo prescrito en el inciso precedente, el juez podrá entregar el cuidado personal del hijo al cónyuge o conviviente civil del padre o madre, siempre que hayan contribuido significativamente a su crianza y educación".

Llama la atención esta ampliación explícita al cónyuge y al conviviente 
civil de cara a la titularidad del cuidado personal. Efectivamente, por primera vez, el legislador señalaría entre los posibles custodios al cónyuge del progenitor y lo haría nombrando a continuación al conviviente civil. De aprobarse la norma, el juez podría, entonces, en caso de inhabilidad de ambos progenitores, otorgar la custodia del menor a este o a aquel -cónyuge o conviviente civil- con tal que hubiese contribuido significativamente a su crianza y educación. Es cierto que dado el tenor del primer inciso de la disposición, cabe entender que uno u otro estarían comprendidos en la expresión otra persona competente, pero puesto que el inciso segundo ordena preferir a los consanguíneos más próximos, especialmente a los ascendientes, actualmente no estarían llamados sino a falta de estos.

\section{CUIDADO PERSONAL Y RELACIÓN DIRECTA Y REgULAR}

Estrechamente ligada al cuidado personal, la relación directa y regular que puede y debe mantener el progenitor que no tiene al menor bajo su cuidado. Tan vinculada que el legislador ordena, en el nuevo artículo 225 CC., que los padres al convenir cuál de ellos detentará el ejercicio del cuidado personal, deberán establecer, a su vez, el régimen de relación directa y regular que mantendrá con los hijos el otro de los progenitores. En tanto que el inciso sexto de la misma disposición prescribe: "Siempre que el juez atribuya el cuidado personal a uno de los padres, deberá establecer, de oficio o a petición de parte, en la misma resolución, la frecuencia y libertad con que el otro padre o madre que no tiene el cuidado personal mantendrá una relación directa y regular con los hijos, considerando su interés superior, siempre que se cumplan los criterios dispuestos en el articulo 229".

Por su parte, la Convención de los derechos del niño, en el artículo $9 \mathrm{~N}^{\circ} 3$ declara: "Los Estados Partes respetarán el derecho del niño que esté separado de uno o de ambos padres a mantener relaciones personales y contacto directo con ambos padres de modo regular, salvo si ello es contrario al interés superior del niño".

En la mayoría de las sentencias examinadas, es posible advertir cómo los jueces cumplen el mandato legislativo, pues, fallando respecto de la atribución del cuidado personal, a continuación resuelven sobre el régimen de relación directa y regular ${ }^{13}$.

${ }^{13}$ En este sentido, Corte Suprema, causas rol 10358-2013, 21334-2014 y 36662014; Corte de Apelaciones de San Miguel, causas rol 887-2013 y 275-2014; Corte de Apelaciones de Santiago, causa rol 1409-2014; Corte de Apelaciones de Valparaíso, causa rol 110-2014; Corte de Apelaciones de Concepción, causa rol 79-2014; Corte de Apelaciones de Coyhaique, causa rol 7-2014. 


\section{Corresponsabilidad, cuidado personal compartido y relación directa y} regular.

Es necesario precisar que corresponsabilidad no significa necesariamente que exista un régimen de custodia compartida - una de las innovaciones de la actual legislación-, sino que padre y madre participen activa y efectivamente en la crianza y educación de sus hijos, de ser ello posible.

La Corte Suprema ${ }^{14}$ afirma categóricamente que la corresponsabilidad no consiste en el establecimiento de un régimen en que ambos padres detenten el cuidado personal, sino más bien, es un principio jurídico que apunta a la necesidad de que los progenitores, toda vez que no sea perjudicial para los hijos, cooperen mancomunadamente en su formación, persiguiendo, con su actuar, el interés superior de ellos. Por tanto, son compatibles la corresponsabilidad y la atribución del cuidado personal en uno de los padres siempre que, con el otro, los hijos mantengan un régimen de relación directa y regular amplio.

2. Sanción al progenitor titular del cuidado personal que obstaculice la relación directa y regular con el otro de los padres.

El legislador, en el artículo 229 inciso $5^{\circ}$, ordena al progenitor, titular del cuidado personal, no obstaculizar el ejercicio del régimen de relación directa y regular con el otro de los padres. Por su parte, la Ley de menores $\mathrm{N}^{\circ} 16.618$, en una manifestación de la relevancia dada al ejercicio de este derechodeber, en el inciso final del artículo 66 prescribe: "El que fuere condenado en procedimiento de tuición, por resolución judicial que cause ejecutoria, a hacer entrega de un menor y no lo hiciere o se negare a hacerlo en el plazo señalado por el tribunal, o bien, infringiere las resoluciones que determinan el régimen de visitas, será apremiado en la forma establecida por el articulo 543 del Código de Procedimiento Civil. En igual apremio incurrirá el que retuviere especies del menor o se negare a hacer entrega de ellas a requerimiento del tribunal".

Curiosamente, la Corte de Apelaciones de Valdivia, en la causa rol 2182008, del 15 de septiembre de 2008, aunque citó el artículo 66 de la Ley de menores, declaró que se permite apremiar al progenitor que incumple el derecho-deber de mantener una relación directa y regular y no a aquel que, detentando el cuidado personal, la impida imputablemente, pues, en este evento, el juez solo puede disponer la forma de recuperar los días perdidos. Quizás la errada interpretación de la disposición de la Ley de Menores haya sido la razón que motivó al legislador de la Ley $\mathrm{N}^{\circ} \mathrm{N}^{\circ} 20.680$ a reiterar dicha norma en el inciso final del nuevo artículo $227 \mathrm{CC}$.

Vigente la nueva ley, la causa rol 81-2014 de la Corte de Apelaciones de La Serena, del 5 de septiembre del presente año, sanciona a la madre, custodia

\footnotetext{
${ }^{14}$ Corte Suprema, causa rol 21334-2014.
} 
del hijo, por haber incumplido el régimen de relación directa y regular de este con su padre y la orden del magistrado de Familia. Por ello, este dispuso, en los autos RIT C 37-2013, con fecha 13 de agosto, como apremio personal, el arresto completo de la madre por quince días y, asimismo, la búsqueda y entrega del niño a su padre por el mismo plazo, mientras durase la referida detención. La Corte de Apelaciones, conociendo el recurso de amparo rol $\mathrm{N}^{\circ} 78-2014$ deducido por la madre, redujo el plazo de arresto de esta y de entrega del niño a su padre, a dos días.

Empero, el juez de Familia decretó el cumplimiento de la referida resolución y dispuso de oficio que el menor permaneciera con su padre los diez días siguientes a los dos ya decretados como arresto para la madre por la Corte, invocando su facultad para actuar de oficio otorgada en el artículo 22 de la Ley $\mathrm{N}^{\circ} 19.968$ y fundándose en el hecho que la madre, durante el año 2014 y hasta la fecha de la resolución, impidió que el menor se relacionase con su padre.

Es oportuno, en este acápite, recordar la sentencia de la Corte de Apelaciones de Puerto Montt -causa rol 197-2013-, la primera de las citadas en este artículo, que, al fallar en relación con la atribución del cuidado personal, desestimó la obstrucción que la titular de este, la madre, efectuaba respecto del ejercicio del régimen de relación directa y regular por parte del padre, aduciendo que esa conducta debía evaluarse en conjunto con el resto de los criterios enumerados en la norma.

\section{Posible abuso sexual porparte del progenitor que ejerce la relación directa} y regular.

El tema del posible abuso sexual del menor no está ausente en los fallos revisados. A propósito de él, cito la sentencia de la Corte de Apelaciones de Santiago, causa rol 1035-2014. Después de una detenida lectura no resulta claro que este se haya producido, pero tampoco puede afirmarse inequívocamente que no haya tenido lugar.

Los padres de la niña presuntamente abusada se sometieron, en agosto de 2011, a una mediación con el objeto de regular los alimentos y el régimen de cuidado personal y relación directa y regular. Conforme al acuerdo, el padre estaría con su hija, los sábados desde las 10.00 hasta las 19.00 hrs., lo cual se cumplió hasta que la madre denunció que la niña había sufrido tocamientos de carácter sexual por parte del padre.

No obstante, si bien inicialmente el tribunal de primera instancia de San Miguel decretó la prohibición de acercamiento del padre a la menor por el lapso de sesenta días, esta decisión luego fue revocada por la Corte de Apelaciones de San Miguel, reponiéndose las cosas al estado que había sido fijado con antelación. La madre reiteradamente incumplió el régimen de 
relación directa y regular arguyendo que, dado lo que había acontecido, el padre no podía llevarse a la niña sino debía visitarla en el domicilio materno. Este denunció, en cada ocasión, la negativa de la madre a entregarle a su hija y solicitó la aplicación de apremios que, en definitiva, fueron decretados. La madre, entonces, recurrió de amparo. Recurso que fue rechazado por considerar los ministros que la madre había dado lugar a dichas medidas por el incumplimiento imputable a las resoluciones judiciales destinadas a hacer efectivo el derecho a una relación directa y regular entre la niña y su padre. Citaron, asimismo, palabras de la madre, que, después de haber denunciado a la policía que la niña había sufrido tocamientos en su vagina, y habiendo sido esta derivada al Servicio Médico Legal, donde se le practicaron exámenes, sin hallar lesiones, ni genitales ni anales, demostrarían su alivio al respecto.

Cabe preguntarse si el interés superior de la niña estuvo suficientemente cautelado, pues del fallo se infiere que los jueces desestimaron un posible abuso debido a que no había huellas físicas de él, pero lo que la madre denunció, en su momento, fueron tocamientos y estos no dejan vestigios en lo somático.

Llama la atención, también, que no se hubiese ordenado, en su oportunidad, practicar pericias, pues respecto del posible abuso solo existe el escueto informe del Servicio Médico Legal.

Se echa de menos, además, la opinión de la menor. ¿Fue escuchada?

En la siguiente sentencia revisada, de la Corte Suprema esta vez, conocemos otro caso en que el padre había sido acusado de abuso sexual por la madre. Aquel había solicitado la determinación del régimen de relación directa y regular respecto de su hijo, en tanto, la madre, se oponía a ello, alegando que el padre había incurrido en conductas constitutivas de abuso sexual contra el menor.

La Corte Suprema rechazó el recurso de casación interpuesto contra la sentencia que confirmaba el fallo de primera instancia que otorgaba la relación directa y regular al padre, con la condición que este se sometiera a una terapia previa. En el caso sub iudice, a diferencia del anterior, se realizaron varias pericias e intervenciones que demostraron que no existiría daño para el menor, sino, al contrario, redundaría en su mejor interés una relación cercana y fluida con el padre. Es notoria la preocupación demostrada por los jueces porque "junto con establecer una relación directa y regular de F.H.H.H. con su bijo T.J.H.P., [...] ha previsto los resguardos necesarios para generar un espacio de seguridad, adaptación y confianza en el menor a través de organismos especializados que deberán analizar todos los antecedentes que han surgido durante la tramitación de este proceso para luego incorporar, paulatinamente y con la supervisión de terceros, a la figura paterna", como señala el considerando $8^{\circ 15}$.

${ }^{15}$ Corte Suprema, causa rol 7870-2013. 


\section{Restricción, suspensión e incumplimiento del régimen de relación directa} y regular.

Habrá ocasiones en las cuales la relación directa y regular deberá restringirse e, incluso, suspenderse. Ello ocurrirá cuando el mantenerla en los términos primitivamente acordados o resueltos sea perjudicial para el menor. En este sentido, la causa rol 4442-2014 de la Corte Suprema, del 17 de septiembre, que rechazó un recurso de casación en el fondo, afirmando en el considerando séptimo: "En ese contexto, es necesario precisar [...] que, por ahora, la restricción temporal del régimen comunicacional, sujeta a la condición que los padres fuesen evaluados e intervenidos, permite resguardar de mejor manera el derecho de la niña a vivir en un ambiente propicio para su desarrollo integral, conforme lo dispone el artículo 27 de la Convención de los derechos del niño".

Así también, la causa rol 2545-2014 de la Corte Suprema, de la misma fecha, que rechazó un recurso de casación en el fondo, en contra de la sentencia de la Corte de Apelaciones de Valparaíso que conservó íntegra la sentencia del juez de la instancia, que había desestimado la pretensión del actor, en orden a aumentar el régimen comunicacional con la madre. Los magistrados, aunque reconocen que los problemas psicológicos y neurológicos del niño derivarían de una carencia afectiva materna, concluyen que este se siente rechazado tanto por la madre como por su hermana, por lo que la ampliación comunicacional que el padre demanda lo perjudicaría, "pues la ausencia de armonia en el hogar se trocaria en infelicidad".

No obstante, las disposiciones legales demuestran la relevancia que se le reconoce a la relación que los padres pueden y deben mantener con sus hijos, -siempre que ello no contraríe su interés superior- sancionando al progenitor que ha incumplido injustificadamente el deber de mantener un régimen de relación directa y regular con sus hijos. En efecto, el legislador de la Ley $\mathrm{N}^{\circ}$ 20.383 - promulgada el 17 de septiembre de 2009 y publicada el 24 del mismo mes- incorporó, como artículo 49 bis a la Ley No 16.618 de Menores, una disposición que priva de la prerrogativa que tienen los padres en el sentido de autorizar o negar la salida del menor al extranjero. Añade la ley que el lapso de permanencia en el extranjero no puede ser mayor de quince días en cada ocasión.

La Corte Suprema, en causa rol 4443-2014, falla en este sentido, rechazando el recurso de casación en el fondo contra la sentencia de la Corte de Apelaciones que, revocando el fallo de primera instancia, había autorizado la salida del país del menor.

\section{Conclusiones}

El análisis de la jurisprudencia posterior a la dictación de la Ley $\mathrm{N}^{\circ} 20.680$ evidencia que la nueva legislación permite a los jueces fallar del modo que, 
en el caso concreto que están conociendo, les parece más idóneo teniendo en vistas la conveniencia del menor. No se necesita, como con la vieja legislación, para cambiar la titularidad del cuidado personal que se demuestre la inhabilidad de quien la detenta, sino que se considera con quién estará mayormente protegida su estabilidad emocional y suficientemente resguardado su normal desarrollo. Es cierto que, con frecuencia, como se puede apreciar de la exégesis de las sentencias, solo cabe escoger aquello que, se estima, le será menos perjudicial.

En suma, del estudio de los fallos, es dable concluir que la ley actualmente vigente posibilita mejor que la anterior resolver los casos de acuerdo con el principio rector en las materias de infancia, cual es, el interés superior del menor.

Otro tema que es pertinente destacar es aquel que dice relación con la cosa juzgada formal. Pues, si bien en el pasado constituían ejemplo paradigmático de sentencias que producían solo cosa juzgada formal aquellas que versaban sobre alimentos, actualmente, se deben mencionar, además, las que se refieren al otorgamiento o mantención de la titularidad del cuidado personal. Reiteradamente, los jueces, al fallar de una u otra manera, enfatizan "por abora, en la actualidad, en estos momentos" o utilizan otra expresión similar, esto es, manteniéndose las condiciones vigentes en el tiempo del litigio ${ }^{16}$.

\section{BibliogRAFÍA}

Abeliuk Manasevich, René, La filiación y sus efectos (Santiago, Editorial Jurídica de Chile, 2000), dos volúmenes.

ACUÑa SAN MARTín, Marcela, El principio de corresponsabilidad parental, en Revista de Derecho de la Universidad Católica del Norte, 20 (2013) 2.

Court Murasso, Eduardo, Nueva Ley de filiación (Santiago, Editorial Jurídica de Chile, 1999).

Lepin Molina, Cristián, Reformas a las relaciones paterno-filiales. Análisis de la Ley $N^{o}$ 20.680, en Revista de Derecho de la Universidad de Chile. Escuela de Postgrado, 3 (2013).

OrRego Acuña, Juan Andrés, Criterios jurisprudenciales recientes en derecho de familia (Santiago, Editorial Metropolitana, 2014).

Quintana Villar, María Soledad, Cuidado personal y relación directa y regular. Legislación y jurisprudencia, en Revista de Derecho de la Pontificia Universidad Católica de Valparaiso, 33 (2009).

Quintana Villar, María Soledad, Derecho de familia (Valparaíso, Ediciones Universitarias de Valparaíso, 2013).

${ }^{16}$ A vía ejemplar, Corte de Apelaciones de Coyhaique, causa rol 7-2014; Corte de Apelaciones de Valparaíso, causa rol 110-2014; Corte de Apelaciones de Concepción, causa rol 79-2014. 
Ramos Pazos, René, Derecho de familia (7 $7^{\text {a }}$ edición actualizada, Santiago de Chile, Editorial Jurídica de Chile, 2010), dos volúmenes.

Somarriva Undurraga, Manuel, Derecho de familia (Santiago, Nascimento, 1963).

Zannoni, Eduardo, Derecho de familia (6 edición actualizada y ampliada, Buenos Aires, Astrea, 2012), dos volúmenes. 